\title{
Quality of survival after artificial ventilation of the newborn
}

\author{
R. DINWIDDIE, D. H. MELLOR, STELLA H. C. DONALDSON, M. E. TUNSTALL, and \\ G. RUSSELL \\ From Aberdeen Maternity Hospital and Royal Aberdeen Children's Hospital
}

\begin{abstract}
Dinwiddie, R., Mellor, D. H., Donaldson, S. H. C., Tunstall, M. E., and Russell, G. (1974). Archives of Disease in Childhood, 49, 703. Quality of survival after artificial ventilation of the newborn. Fifty children now aged 4 to 8 years who required artificial ventilation for respiratory failure in the neonatal period were followed up; $44(88 \%)$ had no serious mental or physical handicap. 35 of the ventilated infants were matched with paired controls who had also had respiratory distress but had not required artificial ventilation. Detailed studies of growth, respiratory and neurological function, and psychological testing revealed only minor differences between the two groups. It is concluded that the quality of survival after artificial ventilation of the newborn justifies the procedure.
\end{abstract}

Respiratory failure is the commonest cause of death in the neonatal period (Registrar General for Scotland, 1971). In recent years, artificial ventilation has been increasingly used in treatment and Swyer (1969) has reviewed its use in several conditions including tetanus neonatorum, meconium aspiration, CNS drug depression, apnoea of prematurity, and particularly the respiratory distress syndrome (hyaline membrane disease). Many different techniques have been used and Daily and Northway (1971) have highlighted the immediate dangers of prolonged tracheal intubation, infection, pneumothorax, and interstitial emphysema. In addition, there is risk of permanent lung damage due to bronchopulmonary dysplasia (Northway, Rosan, and Porter, 1967).

Outerbridge and Stern (1972) noted a significant incidence of bronchiolitis and bronchopneumonia in 74 survivors of the respiratory distress syndrome treated by artificial ventilation, though only one child out of 12 more than 5 years of age had an IQ outside the normal range. Stahlman et al. (1973), in a follow-up of 21 patients surviving after assisted ventilation, found that none had significant developmental delay and that low birthweight was more closely associated with significant damage than artificial ventilation. These studies suggest that artificial ventilation is not associated with a high

Received 19 February 1974. incidence of long-term damage, but further detailed studies of older children, particularly of school age, are required if lesser degrees of disability are to be detected.

The purpose of this study is to assess first the respiratory function and growth patterns, and secondly the neurological and psychological progress of a group of children now aged 4 to 8 years who were treated by artificial ventilation for respiratory failure in the neonatal period.

\section{Patients and methods}

Patients. Between 1964 and 1968, 144 infants were treated by mechanical ventilation in the Special Nursery, Aberdeen Maternity Hospital. All but 8 of these infants were born in this hospital. 53 survived the neonatal period, 1 child died as a cot death aged 1 year, leaving a total of 52 survivors available for follow-up (Table I). The clinical diagnosis and survival rates are shown in Table II. Infants were diagnosed as having idiopathic respiratory distress syndrome if they showed the typical appearances of generalized cyanosis, tachypnoea, intercostal recession, grunting respiration, and the classical ground glass appearance and air bronchogram on chest radiography. In those who died, the diagnosis was confirmed microscopically by the finding of fibrin deposition 'hyaline membranes' in the lungs. Recurrent neonatal apnoea is defined in this study as prolonged periods of cessation of respiration in the absence of clinically or radiologically apparent lung disease. 12 infants required ventilation for respiratory failure due to 
TABLE I

Follow-up of 52 survivors of severe neonatal respiratory failure treated by artificial ventilation

\begin{tabular}{|c|c|c|c|}
\hline & \multirow{2}{*}{ No. } & \multicolumn{2}{|c|}{ Significant handicap } \\
\hline & & Respiratory & $\begin{array}{c}\text { Neurological or } \\
\text { mental }\end{array}$ \\
\hline $\begin{array}{l}\text { No follow-up } \\
\text { Routine hospital follow-up only } \\
\text { Postal reports at time of study } \\
\text { Examined at research clinic-no controls } \\
\text { Examined at research clinic with matched controls }\end{array}$ & $\begin{array}{r}2 \\
5 \\
8 \\
2 \\
35\end{array}$ & $\begin{array}{l}- \\
1 \\
0 \\
0 \\
0\end{array}$ & $\begin{array}{l}- \\
1 \\
0 \\
0 \\
5\end{array}$ \\
\hline Total & 52 & 1 & 6 \\
\hline
\end{tabular}

TABLE II

Diagnosis and survival rates of 144 infants ventilated from 1964-1968

\begin{tabular}{l|r|r|r}
\hline \multicolumn{1}{c|}{ Diagnosis } & Survived & Died & Total \\
\hline Idiopathic respiratory & 31 & 69 & 100 \\
$\quad$ distress syndrome & 13 & 8 & 21 \\
Recurrent neonatal apnoea & 6 & 6 & 12 \\
Pneumonia & 3 & 8 & 11 \\
Other & 53 & 91 & 144 \\
\hline Total & & & \\
\hline
\end{tabular}

pneumonia. Other infants were ventilated because of severe respiratory failure associated with such diverse conditions as hydrops fetalis, septicaemia, and severe congenital heart disease.

When artificial ventilation was first introduced the minimum criteria used were those described by Reid and Tunstall (1966) ( $p \mathrm{H}<7 \cdot 20$ at age 3 hours). In practice, the commonest indication for ventilation was apnoea associated with advanced hyaline membrane disease and in the others the acid-base status was usually considerably worse. Altogether there were 90 infants in this group.

Following on the work of Boston, Geller, and Smith (1966) and Stahlman et al. (1967), which showed the grave prognostic significance of severe hypoxia, the indications for ventilation were changed. Before ventilation was started the infant had to have had at least two major apnoeic attacks requiring resuscitation by endotracheal intubation and manual intermittent positive pressure ventilation, or had to have been persistently cyanosed after at least 15 minutes of breathing oxygen at a concentration of $95 \%$ or more. 54 infants were ventilated according to these criteria.

Nasotracheal intubation was performed in every case and 133 infants were ventilated using the East-Radcliffe ventilator (Type PNA 1) adapted for neonates, as described by Tunstall et al. (1968). This is a timecycled pressure generator (Tunstall et al., 1968) with a fixed inspiratory/expiratory ratio of $0.35 / 1$. and a maximum rate of 37 cycles/minute. The initial settings used were a rate of $37 /$ minute and a pressure of $30 \mathrm{~cm}$ $\mathrm{H}_{2} \mathrm{O}$. Further settings were determined according to the response in blood gases and were achieved by variations in dead space as well as rate and pressure. 9 infants were ventilated using a Bird Mark VIII ventilator with an adult $Q$ circuit and a dummy lung, and 2 infants with both the East-Radcliffe and Bird ventilators. In 13 infants ventilated for more than 48 hours gastrostomy was performed for feeding purposes (Jones and Reid, 1966).

A special clinic was established to review the 37 survivors who were available for detailed follow-up. It was possible to pair 35 of these children with control children matched for sex, birthweight, gestational age, and chronological age as shown in Table III. Each control had also had respiratory distress as a neonate but not severe enough to warrant artificial ventilation. The social class distribution of the two groups is shown in Table IV and there was no significant difference between the two groups.

Respiratory system and growth patterns. A respiratory history was obtained with particular reference to previous hospital admission with lower respiratory

TABLE III

Mean values $( \pm 1 S D)$ for birthweight, gestational age, and age at study

\begin{tabular}{l|c|c|c}
\hline & Ventilated group & Control group & Mean difference per pair \\
\hline Birthweight (g) & $2010( \pm 560)$ & $2065( \pm 600)$ \\
Gestational age (wk) & $33 \cdot 9( \pm 3 \cdot 8)$ & $34 \cdot 5( \pm 3 \cdot 2)$ & 290 \\
Age at study (yr) & $5 \cdot 80( \pm 1 \cdot 00)$ & $5 \cdot 78( \pm 1 \cdot 02)$ & 0.23 \\
\hline
\end{tabular}

Note: 35 in each group, 18 males: 17 females. 
TABLE IV

Social class distribution

\begin{tabular}{l|c|c}
\hline \multicolumn{1}{c|}{ Social class } & Ventilated & Controls \\
\hline I-IIIA & 5 & 9 \\
IIIB & 9 & 8 \\
IIIC & 4 & 4 \\
IV & 10 & 8 \\
V & 3 & 3 \\
Illegitimate & 4 & 3 \\
\hline Total & 35 & 35 \\
\hline
\end{tabular}

$\chi^{2}=1.567, \mathrm{df}=5, \mathrm{P}=\mathrm{NS}$.

tract infection. $X$-ray of the chest was followed by measurement of height, weight, occipitofrontal head circumference, biacromial width, and chest circumference at midrespiration. In co-operative children, simple tests of lung function were performed including forced vital capacity (FVC) and forced expiratory volume in 0.75 seconds (FEV 0.75 ) measured on a Vitalograph single breath spirometer, and these results were then converted to BTPS. Peak expiratory flow rate (PEFR) was measured using a Wright Peak Flow Meter.

For each measurement a 'predicted' normal value was calculated using standards obtained on normal children by other workers. The data of Tanner, Whitehouse, and Takaishi (1966) were used for height and weight, the 50th centile for age being taken as the 'predicted value'. For head circumference the 50th centile values for age given by Nellhaus (1968) were used as the 'predicted' values. 'Predicted' biacromial width was calculated from height using the regression equation of Howatt and DeMuth (1965). The 'predicted' chest circumference against height was taken from the 50th centile values given by Cooke (1968). The values obtained for the respiratory function tests were expressed as a percentage of the mean values for height obtained by Lunn (1965).

Neurological examination. The form of the systematic neurological examination was based closely on methods described by Paine and Oppé (1966), Rutter, Graham, and Yule (1970a), and Touwen and Prechtl (1970). Inquiry was first made as to previous fits or other history suggesting neurological disorder. Speech articulation was judged on the basis of conversation elicited during the examination. Visual acuity was tested using the Stycar single letter cards (Sheridan, 1960), and hearing with the Stycar picture vocabulary test (Sheridan, 1958). Cranial nerves, motor and reflex functions were examined in the conventional way. Taking into account the child's age, careful observation of manipulation, posture, and locomotion was made for evidence of minor degrees of motor dysfunction (Touwen and Prechtl, 1970). Constructional abilities were assessed using the matchstick test described by Rutter $e t$ al. (1970a). At the completion of the neurological examination an overall rating was given to each child using four categories which took into account neuro- logical abnormality and resulting physical handicap. For this purpose uncomplicated mental retardation was not rated as a neurological disorder.

Category 1. No abnormal neurological findings.

Category 2. Neurological findings of slight or doubtful significance.

Category 3. Definite neurological disorder but producing little or no physical handicap.

Category 4. Definite and obviously handicapping neurological disorder.

Psychological assessment. The parents of each child were asked to complete a standardized and previously validated behaviour questionnaire (Rutter, Tizard, and Whitmore, 1970b) before attending the research clinic. A score on this questionnaire of more than 12 was taken to indicate behavioural difficulties. At the clinic the Illinois Test of Psycholinguistic Abilities (ITPA) described by Kirk, McCarthy, and Kirk (1968) was used. This test-consisting of 10 subtests-is designed to isolate defects in channels of language input and output. As a result of the child's performance on these various subtests a Psycholinguistic Quotient (PLQ) is computed which is comparable to a ratio IQ with a mean value for the normal population of 100 .

The Bender Motor Gestalt Test (Koppitz, 1970) was also administered to all the children. This is a test of visual motor perception and is generally thought to be valuable in the diagnosis of neurological impairment (Hanvick, 1953; Shaw and Cruickshank, 1956).

\section{Results}

There were 52 survivors in all and the follow-up obtained on them is shown in Table I. At the time of the study, 7 children could not be traced, though 5 of these had been seen in the routine follow-up clinic at ages varying from 5 to 13 months and some information was therefore available as to the outcome. 3 of these children had been discharged as normal and 1 child had radiological evidence of persistent right lower lobe collapse at the age of 1 year. The fifth child who required ventilation for 44 days was last seen aged 10 months when he had had 5 readmissions to hospital for lower respiratory tract infection and showed significant developmental delay.

Postal reports were received from the parents of 8 children who had left the district. All these children were attending normal school and none was reported by the family doctor to have any significant respiratory problems. 1 child, now living abroad, had had an operation for squint and was receiving treatment for 'epilepsy', though he was performing adequately at school.

Suitable controls could not be found for 2 of the 37 children seen at the clinic. 1 child, aged $4 \cdot 6$ years, was completely normal on physical assessment and had a PLQ of 98 . The other child, aged 
TABLE V

Respiratory function and growth patterns. Mean value ( $\pm S E$ of mean)

\begin{tabular}{|c|c|c|c|c|c|c|}
\hline & \multirow{2}{*}{ No. of pairs } & \multirow{2}{*}{ Ventilated } & \multirow{2}{*}{ Controls } & \multicolumn{2}{|c|}{$\%$ of predicted value } & \multirow{2}{*}{$\begin{array}{l}\text { Actual ventilated } \\
\text { value/actual } \\
\text { control value }\end{array}$} \\
\hline & & & & Ventilated & Controls & \\
\hline $\begin{array}{l}\text { Height } \\
\text { Weight } \\
\text { Head circumference } \\
\text { Biacromial width } \\
\text { Forced vital capacity } \\
\text { Peak expiratory flow rate } \\
\text { FEV } 0.75 \\
\text { FEV } 0.75 / \text { FVC }\end{array}$ & $\begin{array}{l}35 \\
35 \\
35 \\
34 \\
23 \\
24 \\
20 \\
20\end{array}$ & $\begin{array}{c}110.8 \mathrm{~cm} \\
19.9 \mathrm{~kg} \\
51.0 \mathrm{~cm} \\
24.8 \mathrm{~cm} \\
1.161 . \\
1651 . / \mathrm{min} \\
1.091 . \\
91 \%\end{array}$ & $\begin{array}{c}110 \cdot 4 \mathrm{~cm} \\
19 \cdot 0 \mathrm{~kg} \\
51 \cdot 5 \mathrm{~cm} \\
24 \cdot 4 \mathrm{~cm} \\
1 \cdot 191 . \\
1691 . / \mathrm{min} \\
1 \cdot 121 . \\
97 \%\end{array}$ & $\begin{array}{r}98( \pm 0 \cdot 8) \\
98( \pm 2 \cdot 1) \\
100( \pm 0 \cdot 7) \\
102( \pm 0.9) \\
83( \pm 2 \cdot 6) \\
92( \pm 3 \cdot 2) \\
91( \pm 3 \cdot 6)\end{array}$ & $\begin{array}{r}98( \pm 0 \cdot 6) \\
95( \pm 1 \cdot 8) \\
101( \pm 0 \cdot 5) \\
100( \pm 0 \cdot 9) \\
90( \pm 2 \cdot 8) \\
95( \pm 3 \cdot 7) \\
97( \pm 2 \cdot 7)\end{array}$ & $\begin{array}{l}1.01( \pm 0.01) \\
1.05( \pm 0.03) \\
0.99( \pm 0.01) \\
1.02( \pm 0.01) \\
1.00( \pm 0.05) \\
1.04( \pm 0.06) \\
1.00( \pm 0.06)\end{array}$ \\
\hline
\end{tabular}

$5 \cdot 9$ years, who had normal pulmonary function and a PLQ of 99, had bilateral nerve deafness not requiring a hearing aid. The 35 children for whom matched controls were available started ventilation at a mean age of 29 hours (range 2-168 hours) and the mean duration of ventilation was 66 hours (range 2-178 hours). The results for these 35 matched pairs are as follows.

Respiratory function and growth. 27 children in the ventilated group and 28 in the control group had no abnormality on chest $x$-ray. 8 of the ventilated group and 7 controls had slight accentuation of lung markings, particularly in the perihilar area. However, these findings were not considered to be significant of permanent damage. 1 child in the ventilated group is an asthmatic and has had several hospital admissions. 3 other children in the ventilated group required a total of 4 readmissions to hospital because of lower respiratory tract disease during the first year of life. In the control group 1 child, aged 9 months, had pulmonary tuberculosis and 3 other children, aged 7,37, and 38 months respectively, were readmitted to hospital with lower respiratory tract infection. As in the ventilated group, none has since required hospital treatment for lower respiratory tract disease. The results of the other measurements are shown in Table V. In both groups the mean values for height, weight, head circumference, chest circumference, and biacromial width were within normal limits. The mean value for FVC in the ventilated group was lower than the mean expected for height, though this may have been due to poorer co-operation in the performance of this test by the youngest children since there was a higher value for the $\mathrm{FEV}_{0.75} / \mathrm{FVC}$ ratio than that obtained by Lunn (1965) in children of this age. A wide range of results was obtained for the various lung function tests in both groups and there was no significant difference between them (for FVC, $t=0.42,0.7>P>0.6$; for $\mathrm{FEV}_{0.75}$, $t=0.36,0.7>P>0 \cdot 6)$.

Neurological examination. Table VI shows the overall neurological ratings in the ventilated and control groups. It will be seen that there were a few more neurologically abnormal children in the ventilated group. The difference was not statistically significant and was mainly due to a slight excess of children in the ventilated group, showing doubtful neurological abnormalities which included articulatory speech defects, minor degrees of motor dysfunction, constructional difficulties, squint, and febrile convulsions, singly or in combination.

TABLE VI

Results of neurological examination

\begin{tabular}{|c|c|c|c|c|}
\hline Category & $\begin{array}{l}\text { Neurological } \\
\text { abnormalities }\end{array}$ & Handicap & Ventilated group & Control group \\
\hline $\begin{array}{l}1 \\
2 \\
3 \\
4\end{array}$ & $\begin{array}{l}\text { None } \\
\text { Doubtful } \\
\text { Definite } \\
\text { Definite }\end{array}$ & $\begin{array}{l}\text { None } \\
\text { None or slight } \\
\text { None or slight } \\
\text { Moderate or severe }\end{array}$ & $\begin{array}{r}14 \\
14 \\
5 \\
2\end{array}$ & $\begin{array}{r}21 \\
9 \\
4 \\
1\end{array}$ \\
\hline Total & & & 35 & 35 \\
\hline
\end{tabular}

$\chi^{2}=2 \cdot 82, \mathrm{df}=2$ (last 2 rows combined) $P=\mathrm{NS}$. 
There were 7 children in the ventilated group who showed definite neurological abnormalities. 2 of these were physically handicapped, 1 child having a spastic diplegia, 1 child having a spastic hemiplegia. This latter child suffered an episode of severe hypernatraemic dehydration at 4 months of age and it is possible that his cerebral palsy was caused then and not in the neonatal period. Of the remaining 5 children without significant handicap, 1 suffered from infrequent grand mal epilepsy, 2 had mild spastic hemiparesis, and 2 showed evidence of cerebellar dysfunction with intentional tremor. There were 5 children in the control group who showed definite neurological abnormalities. 1 child was physically handicapped with a spastic hemiplegia. Of the remaining 4 children, one showed nystagmus and mild optic atrophy (corrected visual acuity $6 / 18$ bilaterally), 1 had bilateral nerve deafness but this was not severe enough to require a hearing aid, 1 had infrequent grand mal epilepsy, and 1 had a very mild spastic paraparesis.

Psychological assessment. 11 children in the ventilated group and 8 in the control group had scores on the behaviour questionnaire indicative of behavioural difficulties. 3 children failed to complete the ITPA, 1 because of lack of cooperation and 2 because of gross retardation, all were in the ventilated group. A ' $t$ ' test was used to compare the PLQs of the remaining 32 pairs and no significant difference was found between them. However, when a PLQ was estimated for each of the 3 incompletely tested children (from the results of the subtests completed), the mean PLQ for the ventilated group was $88(S D \pm 19 \cdot 5)$ and the mean for the control group was $97\left(S D_{ \pm 16} \cdot 5\right)$. The paired ' $t$ ' test now showed that the PLQs for the control group were significantly higher than those of the ventilated group $(P<0.05)$. 5 children in the ventilated group had PLQs of less than 70. 3 of these were ventilated because of persistent respiratory acidosis and 2 because of apnoea associated with severe hypoxia. Table VII shows that in spite of the significant difference between the two groups, 30 of the 35 ventilated children ( $86 \%$ ) had PLQs over 70.

The Fig. shows the means of the subtest scores for each group. Though there were differences between the results obtained from both ventilated and control groups and the normal population, the only subtest which showed a significant difference between the two groups was the Auditory Reception subtest. In this subtest the ventilated group did significantly less well than their paired controls $(\mathrm{P}<0 \cdot 05)$.
TABLE VII

Psycholinguistic quotient (PLQ)

\begin{tabular}{c|c|c}
\hline PLQ & Ventilated & Control \\
\hline$<71$ & 5 & 1 \\
$71-85$ & 10 & 9 \\
$86-100$ & 13 & 10 \\
$101-115$ & 6 & 9 \\
$116-130$ & 1 & 5 \\
$>130$ & 0 & 1 \\
\hline Total & 35 & 35 \\
\hline
\end{tabular}

$t=2 \cdot 23, d f=34, P<0 \cdot 05$.

The Bender Gestalt records were scored after Koppitz (1970), and a paired ' $t$ ' test showed that there was no significant difference between the two groups. Comparison with mean scores for the normal population of equivalent age showed that neither the ventilated group nor the control group had the consistently high scores which might indicate the presence of brain damage.

Incidence of serious mental and neurological handicap. When the results of the neurological examination are taken together with the psychological assessment the incidence of serious mental and neurological handicap can be seen in the two groups (Table VIII). For this purpose mental handicap was defined as a PLQ of less than 70 and a child had to be in the neurological category 4 to be called neurologically handicapped. In the ventilated group 5 children were mentally handicapped, of whom 2 were also neurologically handicapped. In the control group, 1 child was mentally and 1 child neurologically handicapped. On the other hand, 30 of the ventilated children $(86 \%)$ and 33 of the control children (94\%) had no serious mental or neurological handicap.

\section{Discussion}

The introduction of neonatal intensive care techniques has led to the survival of infants who would otherwise have died with more conservative medical care and it might not be surprising to find that a significant number of these survivors were damaged. However, Rawlings et al. (1971) have shown encouraging long-term results in infants discharged from a modern special care nursery.

It has been suggested that artificial ventilation in particular is likely to keep alive babies with serious physical and mental handicap and some paediatric centres will not use this technique for this reason. At the present time there is relatively little information available on the long-term effects of this 


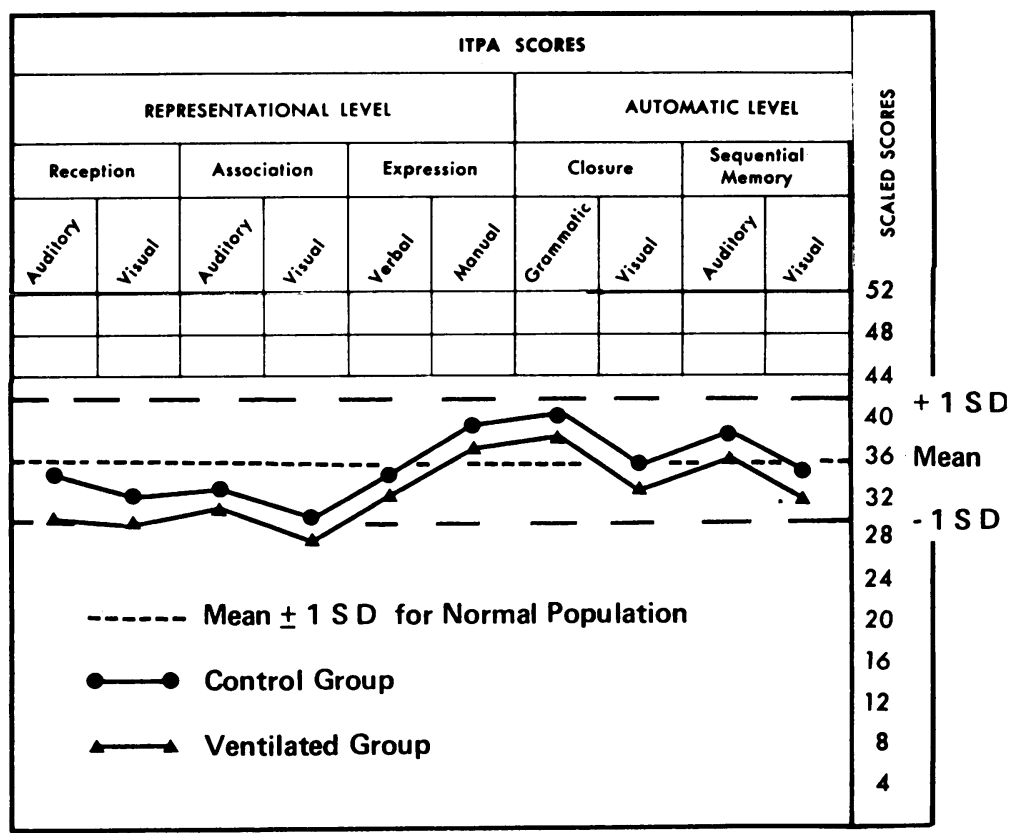

FIG.-Illinois Test of Psycholinguistic Abilities subtest scores for ventilated and control children seen at the clinic.

treatment, though Outerbridge and Stern (1972) and Stahlman et al. (1973), in long-term studies of infants treated by negative pressure ventilation, have shown that the incidence of serious mental and physical handicap is low. Of the 50 ventilated children for whom some follow-up data were available, $6(12 \%)$ had serious mental or neurological handicap.

Twenty children (57\%) out of the 35 in each of the groups seen at the clinic had a birthweight of less than $2000 \mathrm{~g}$ and it is therefore encouraging that there was no difference in growth patterns either between the two groups or between each group and the normal population. Stahlman et al. (1973) reported follow-up to school entry of 85 children who had clinical hyaline membrane disease in the newborn period, including 21 treated by intermittent negative pressure ventilation. In this ventilated group they found no evidence of cerebral palsy, microcephaly, or retrolental fibroplasia, and a somewhat lower incidence of mental handicap than in our group. However, they also noted that 19 of their 21 ventilated patients $(90 \%)$ had weights at 6 years of age below the 50th centile, though more than half of this group had a birthweight of greater than $2000 \mathrm{~g}$. These differences may be because some of the children in our ventilated group were treated for conditions other than clinical hyaline membrane

TABLE VIII

Incidence of serious mental and neurological handicap

\begin{tabular}{l|r|r|r|}
\hline & Ventilated \\
\hline 1. No serious mental or neurological handicap & 30 & 33 \\
2. Neurological handicap alone & 0 & 3 & 1 \\
3. Mental handicap alone & 2 & 35 \\
4. Mental and neurological handicap & 35 & 35 \\
\hline Total & & 35 \\
\hline
\end{tabular}

$\chi^{2}$ (mental handicap) $=1 \cdot 61, \mathrm{df}=1,0.10>\mathrm{P}>0.05$ (columns 1 and 2 combined, columns 3 and 4 combined). 
disease, and perhaps also to differences in socioeconomic factors. The more normal weight distribution in our ventilated group might also be due to the fact that it is easier to feed infants on intermittent positive pressure ventilation either orally or via gastrostomy than to feed infants on intermittent negative pressure ventilation. Total intravenous feeding has superseded the use of gastrostomy in many centres and adequate early nutrition should therefore be less of a problem in the future.

Unfortunately, not all the children studied performed the pulmonary function tests adequately and though there was no evidence of abnormal lung function in those tested in the ventilated group it is possible that some of those who did not co-operate might have had diminished lung function. However, measurement of chest circumference and chest radiography again revealed no difference between the ventilated group, the control group, or the normal population. Apart from 1 child with asthma in the ventilated group, no child in either group now has any detectable respiratory disease.

Although 30 of the 35 children $(86 \%)$ in the ventilated group had no serious handicap, $18(51 \%)$ had evidence of slight or doubtful neurological abnormality, a borderline PLQ of 71-85 or evidence of behavioural disorder singly or in combination. Some of these children may be at risk of having difficulties with educational or social adaptation. To place this in proper perspective, 16 of the control group $(46 \%)$ showed similar findings indicating that these less serious disabilities are probably not a direct effect of artificial ventilation.

The pattern of results for the ITPA subtests is shown in the Fig., where it can be seen that the scores for the ventilated group 'shadow' those of the control group in all subtests except the Auditory Reception subtest in which the ventilated group did significantly less well than the control group. This suggests that the ventilated children can derive meaning from verbally presented material less well than the control children. The mean for each subtest differs from the mean for the normal population by varying amounts, and suggests that neither group is truly representative of the normal population. This could be a result of the neonatal respiratory difficulties, the low birthweight, or the preterm delivery. Differences between the groups and the normal population cannot therefore be attributed to artificial ventilation.

This study indicates that the majority of our survivors of neonatal artificial ventilation, many of whom would otherwise have died, were left with no serious mental or physical handicap. Intermittent positive pressure ventilation can be recommended as a rewarding method of treatment for the newborn infant with severe respiratory failure.

We thank Professor R. G. Mitchell for permission to carry out this study; Mr. D. Clark for his advice on the psychological tests; Mr. A. M. Stewart for reporting the radiological examinations; Dr. G. Hems for statistical advice; Mr. G. W. Horobin for help with social classification; Mrs. S. Todd, Mrs. K. Middleton, Miss L. Deans, and Mrs. I. Forbes for secretarial help; and Mrs. S. Jones and Miss A. Sinclair for technical and nursing assistance. We particularly acknowledge the help given to us by the general practitioners of all the patients. Fig. 1 is reproduced by permission of the University of Illinois Press. This study was supported by grants from the Medical Research Council and the North Eastern Regional Hospital Board (Scotland).

REFERENCES

Boston, R. W., Geller, F., and Smith, C. A. (1966). Arterial blood gas tensions and acid-base balance in the management of the respiratory distress syndrome. Fournal of Pediatrics, 68, 74.

Cooke, R. E. (1968). The Biologic Basis of Pediatric Practice, p. 1698. McGraw-Hill, New York.

Daily, W. J. R., and Northway, W. H. (1971). Perspectives in mechanical ventilation of the newborn. In Advances in Pediatrics, Vol. 18, p. 253. Ed. by I. Schulman. Year Book Medical Publishers, Chicago.

Hanvick, L. J. (1953). A note on rotations in the Bender Gestalt Test as predictors of E.E.G. abnormalities in children. fournal of Clinical Psychology, 9, 399.

Howatt, W. F., and DeMuth, G. R. (1965). Configuration of the chest. Pediatrics, 35, 177 .

Jones, P. F., and Reid, D. H. S. (1966). Gastrostomy in neonatal respiratory failure. Lancet, $2,573$.

Kirk, S. A., McCarthy, J. J., and Kirk, W. D. (1968). The Illinois Test of Psycholinguistic Abilities. University of Illinois Press, Urbana, Illinois.

Koppitz, E. M. (1970). The Bender Gestalt Test for Young Children. Grune and Stratton, New York.

Lunn, J. E. (1963). Respiratory measurements of 3,556 Sheffield schoolchildren. British fournal of Preventive and Social Medicine, 19, 115.

Nellhaus, G. (1968). Head circumference from birth to eighteen years. Pediatrics, 41, 106

Northway, W. H., Rosan, R. C., and Porter, D. Y. (1967) Pulmonary disease following respirator therapy of hyalinemembrane disease: bronchopulmonary dysplasia. New England fournal of Medicine, 276, 357.

Outerbridge, E. W., and Stern, L. (1972). Developmental follow-up of artificially ventilated infants with neonatal respiratory failure. (Abst.) Pediatric Research, 6, 412.

Paine, R. S., and Oppé, T. E. (1966). Neurological Examination of Children. Spastics Society with Heinemann, London.

Rawlings, G., Reynolds, E. O. R., Stewart, A., and Strang, L. B. (1971). Changing prognosis for infants of very low birth weight. Lancet, 1, 516.

Registrar General for Scotland (1971). Annual Report No. 117, Part I, p. 381. H.M.S.O., Edinburgh.

Reid, D. H. S., and Tunstall, M. E. (1966). The respiratory distress syndrome of the newborn. Anaesthesia, 21, 72.

Rutter, M., Graham, P., and Yule, W. (1970a). A Neuropsychiatric Study in Childhood. Spastics Society with Heinemann, London.

Rutter, M., Tizard, J., and Whitmore, K. (1970b). Education, Health and Behaviour. Longman, London.

Shaw, M. C., and Cruickshank, W. M. (1956). The use of the Bender Gestalt test with epileptic children. Fournal of Clinical Psychology, 12, 192.

Sheridan, M. D. (1958). Simple clinical hearing-tests for very young or mentally retarded children. British Medical fournal, 2. 999. 
Sheridan, M. D. (1960). Vision screening of very young or handicapped children. British Medical fournal, 2, 453.

Stahlman, M. T., Battersby, E. J., Shepard, F. M., and Blankenship, W. J. (1967). Prognosis in hyaline-membrane disease. New England fournal of Medicine, 276, 303.

Stahlman, M. T., Hedval, G., Dolanski, E., Faxelius, G., Burko, H., and Kirk, V. (1973). A six-year follow up of clinical hyaline membrane disease. Pediatric Clinics of North America, 20, 433.

Swyer, P. R. (1969). An assessment of artificial respiration in the newborn. Report of 59th Ross Conference on Pediatric Research, p. 25. Ross Laboratories, Columbus.

Tanner, J. M., Whitehouse, R. H., and Takaishi, M. (1966). Standards from birth to maturity for height, weight, height velocity, and weight velocity: British children, 1965. Part I. Archives of Disease in Childhood, 41, 454.

Touwen, B. C. L., and Prechtl, H. F. R. (1970). The Neurological Examination of the Child with Minor Nervous Dysfunction. Spastics Society with Heinemann, London.

Tunstall, M. E., Cater, J. I., Thomson, J. S., and Mitchell, R. G. (1968). Ventilating the lungs of newborn infants for prolonged periods. Archives of Disease in Childhood, 43, 486.

Correspondence to Dr. R. Dinwiddie, Department of Child Health, University of Aberdeen, Foresterhill, Aberdeen AB9 2ZD.

The following articles will appear in future issues of this journal:

Recurrence of febrile convulsions. S. J. Wallace.

Growth in children with 45,XO Turner's syndrome. C. G. D. Brook, G. Mürset, M. Zachmann, and A. Prader.

Distending pressure in infants with respiratory distress syndrome. J. D. Baum and N. R. C. Roberton.

Posthaemorrhagic hydrocephalus : diagnosis, differential diagnosis, treatment, and long-term results. J. Lorber and U. S. Bhat.

Plasma renin activity in acute poststreptococcal glomerulonephritis and the haemolytic-uraemic syndrome. H. R. Powell, E. Rotenberg, A. L. Williams, and D. A. McCredie.

Chromosome studies in investigation of stillbirths and neonatal deaths. R. Bauld, G. R. Sutherland, and A. D. Bain.

Uncomplicated hyperparathyroidism. B. M. Frier and V. J. Marrian.

Congenital rickets due to maternal vitamin D deficiency. M. Moncrieff and T. O. Fadahunsi. 